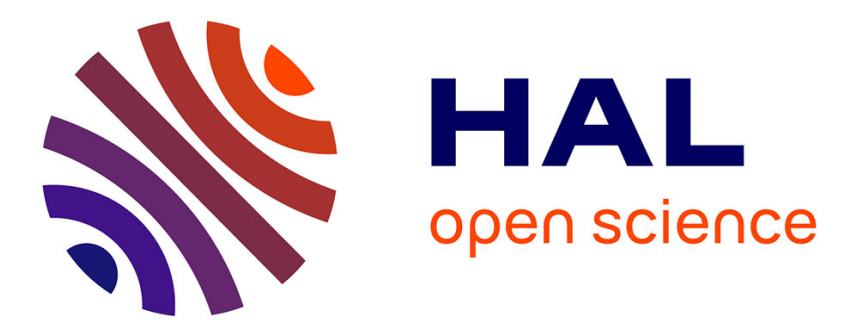

\title{
Monitoring seasonal snow dynamics using ground based high resolution photography (Austre Lovenbreen, Svalbard, $\left.79^{\circ} \mathrm{N}\right)$
}

Eric Bernard, Jean-Michel Friedt, Florian Tolle, Madeleine Griselin, Gilles Martin, Dominique Laffly, Christelle Marlin

\section{To cite this version:}

Eric Bernard, Jean-Michel Friedt, Florian Tolle, Madeleine Griselin, Gilles Martin, et al.. Monitoring seasonal snow dynamics using ground based high resolution photography (Austre Lovenbreen, Svalbard, $\left.79^{\circ} \mathrm{N}\right)$. ISPRS Journal of Photogrammetry and Remote Sensing, 2013, 75, pp.92-100. 10.1016/j.isprsjprs.2012.11.001 . hal-00806226

\section{HAL Id: hal-00806226 \\ https://hal.science/hal-00806226}

Submitted on 17 Feb 2014

HAL is a multi-disciplinary open access archive for the deposit and dissemination of scientific research documents, whether they are published or not. The documents may come from teaching and research institutions in France or abroad, or from public or private research centers.
L'archive ouverte pluridisciplinaire HAL, est destinée au dépôt et à la diffusion de documents scientifiques de niveau recherche, publiés ou non, émanant des établissements d'enseignement et de recherche français ou étrangers, des laboratoires publics ou privés. 


\title{
Monitoring seasonal snow dynamics using ground based high resolution photography (Austre Lovénbreen, Svalbard, $79^{\circ} \mathrm{N}$ )
}

\author{
Bernard É. \\ UMR ThéMA, CNRS/Université de Franche-Comté, Besançon, France \\ Friedt J. M. \\ UMR FEMTO-ST, CNRS/Université de Franche Comté, Besançon, France \\ Tolle F. \\ UMR ThéMA, CNRS/Université de Franche-Comté, Besançon, France \\ Griselin M. \\ UMR ThéMA, CNRS/Université de Franche-Comté, Besançon, France \\ Martin G. \\ UMR FEMTO-ST, CNRS/Université de Franche Comté, Besançon, France \\ Laffly D. \\ GEODE, Université de Toulouse le Mirail, France \\ Marlin C. \\ UMR IDES, CNRS/Université Paris-Sud, Orsay, France
}

\begin{abstract}
Arctic glaciers are reliable indicators of global climate changes. However, monitoring snow and ice dynamics in Arctic regions is challenging: some fast but key events can be missed since they are short in time but significant in the hydrological budget.

In the context of long term monitoring with high temporal and spatial resolutions of the snow cover dynamics, automated digital cameras were installed around the Austre Lovénbreen glacier basin (Spitsbergen, Norway, $79^{\circ} \mathrm{N}$ ). Despite data losses due to rough weather conditions and control electronics failure, a dataset of 2411 pictures (out of an expected 3294) was gathered over a one year hydrological period to assess the snow coverage of the glacier as a function of time with daily resolution. $73 \%$ of the total number of expected
\end{abstract}


images was thus recorded, with gaps associated with temporary electronics or data storage failure.

The 6 camera stations oriented so as to observe the glacier itself provide a surface coverage of $96 \%$. Furthermore, geometric corrections of the pictures, using reference ground control points located on the glacier through GPS receivers, yield a quantitative information from initially qualitative images. Projecting the resulting mosaic of the images gathered from 6 cameras on a GIS allows for the precise monitoring of ice-related processes, and especially the snow coverage evolution over time. This paper summarizes our current understanding of such dynamics, based on the analysis of daily mosaics of images allowing for the observation of both long term evolution on the seasonal scale and the short term events on a weekly scale. Such results demonstrated over one typical full hydrological season (April to October 2009) that snow coverage evolves following discrete steps, either due to water precipitation or warm events, with a snow coverage ranging from 100\% (april) to $37 \%$ (september). Keywords: Ground based camera, snow cover dynamics, in-situ sensing

\section{Introduction}

The results described in this paper are considered within the context of global climate change. Alpine-type polar glaciers are considered reliable indicators of global warming [20, $22,10,18,7]$. Indeed, small polar hydro-systems exhibit significant responses to climatic anomalies. One original aspect of the present study is the very local scale of the analysis in order to understand in great details the phenomena under investigation. While classical analysis of global processes is usually performed on a wide glacier range [13, 9], such detailed analysis is more unusual to analyze a polar hydro-system. This originality is even more significant in an Arctic environment, where extreme weather conditions yield additional challenges for the continuous monitoring. Thus, the basic conclusion is that satellite imagery is insufficient to investigate the snow and ice dynamics of a glacier basin at daily scale, both due to cost and availability of materials as well as insufficient spatial and time resolutions.

Hence, in the framework of the 2006-2010 International Polar Year program HydroSensor-FlOWS, a sensor network has been setup over the $10 \mathrm{~km}^{2}$ large Austre Lovénbreen 
glacier basin (Fig. 1) at altitudes ranging from sea level to $450 \mathrm{~m}$ Above Sea Level. Dedicated automated digital cameras were installed at strategic spots of the glacier basin providing image coverage of the whole glacier (Fig. 2). While designed to provide continuous informations on the hydroglaciological dynamics, this setup also provides a continuous monitoring of the snow cover dynamics $[11,21,3,5,12,15]$. Unlike previous studies [11], this project focuses on the use of high resolution digital camera for snow cover monitoring, and hence requires more detailed signal processing than vegetation cover estimate. High resolution digital camera provide sub-meter resolution over the whole field of view, a result only accessible with sensor resolutions above the 10 Mpixel range [12]. Furthermore, unlike previous studies using oblique view [13], geometric correction is used for a quantitative analysis of this dataset, with a high fraction of the area of the glacier covered by overlapping pictures taken by different cameras in a mosaique of projected pictures.

Our purpose here is to observe snow and ice melt dynamics and assess its contributions to the global budget of this characteristic small polar hydro-system. The signal processing sequence is based on qualitative datasets from which meaningful quantitative informations are extracted. By applying geometrical corrections to the ground-based oblique view pictures, mosaics of zenithal projected maps are obtained. After describing the image processing steps, we will exhibit the first results of the application of this dataset to snow cover monitoring: the assessment is performed on the 2009 hydrological season, whose short visible melt period extends from the beginning of July to the end of August.

Hydrological dynamics of a drainage basin are defined by several factors. We focus on the upstream aspect of the snow and ice contributions to these processes. Although satellite imagery is available, the phenomena under investigation require improved time and space resolutions. While informations gathered through remote sensing is rich by itself, it must be complemented with our ground-based pictures, better suited to our problem due to their improved time and spatial resolutions. Indeed, the available sensor network and the small basin area are consistent with this detailed monitoring, and justify the use of ground based high resolution pictures, assuming that the appropriate digital image processing is applied 


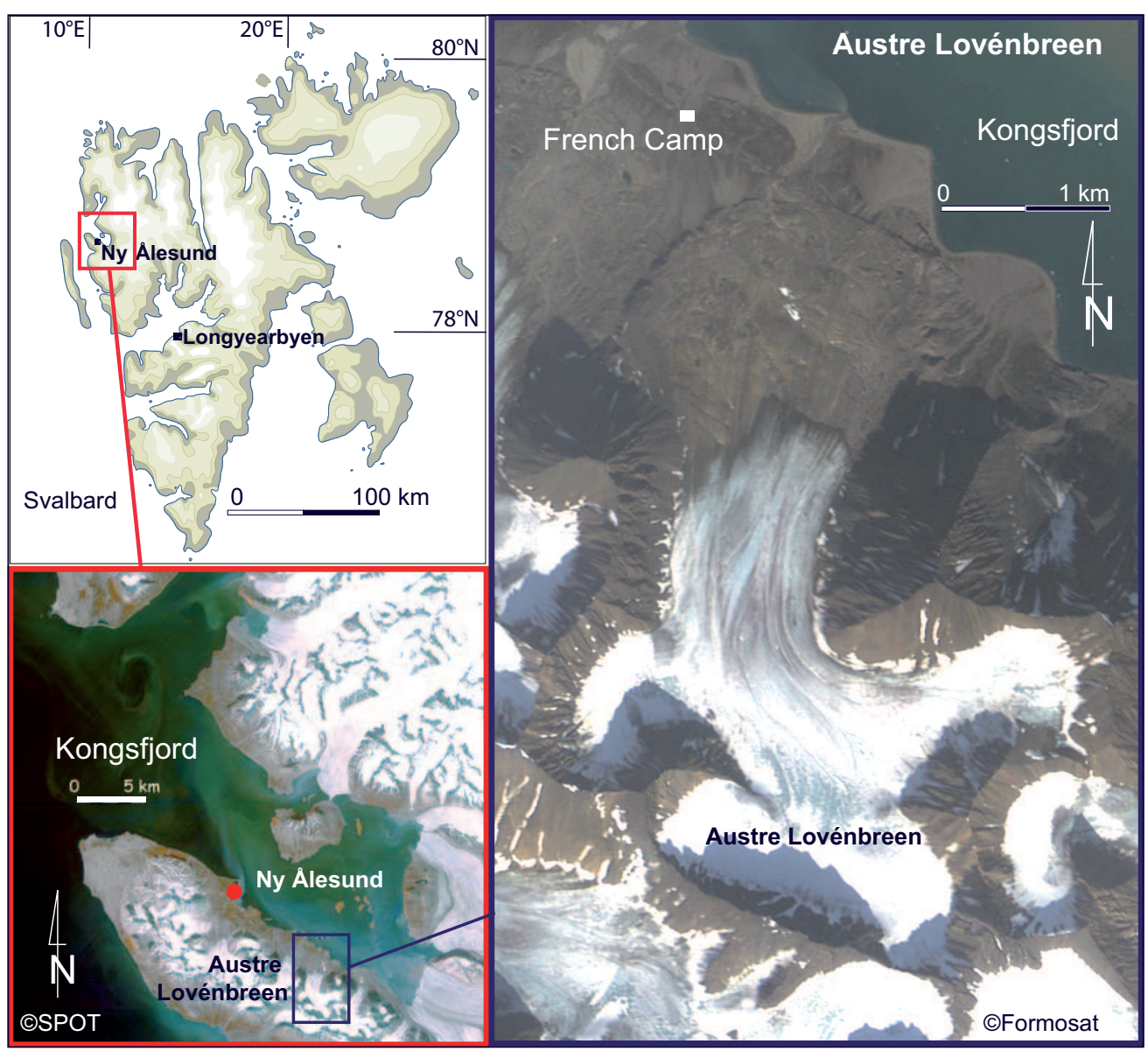

Figure 1: Located $79^{\circ} \mathrm{N}$, the $10 \mathrm{~km}^{2}$ Austre Lovénbreen glacier basin is the subject of these investigations.

as will be described here.

\section{Materials and methods}

\subsection{Instrument setup}

Six automated instruments located around the Austre Lovénbreen glacier provide the data needed for this study. The instruments are based on a commercial off the shelf Leica DLux 3 or D-Lux 4 camera with 10 Mpixel resolution. These compact cameras were selected for their excellent lens, high resolution at the time the program was started (2007), and availability of a SD-card non-volatile storage medium (requiring only nine wires between the dry airtight enclosure in which the cameras are located and the user-accessible memory 


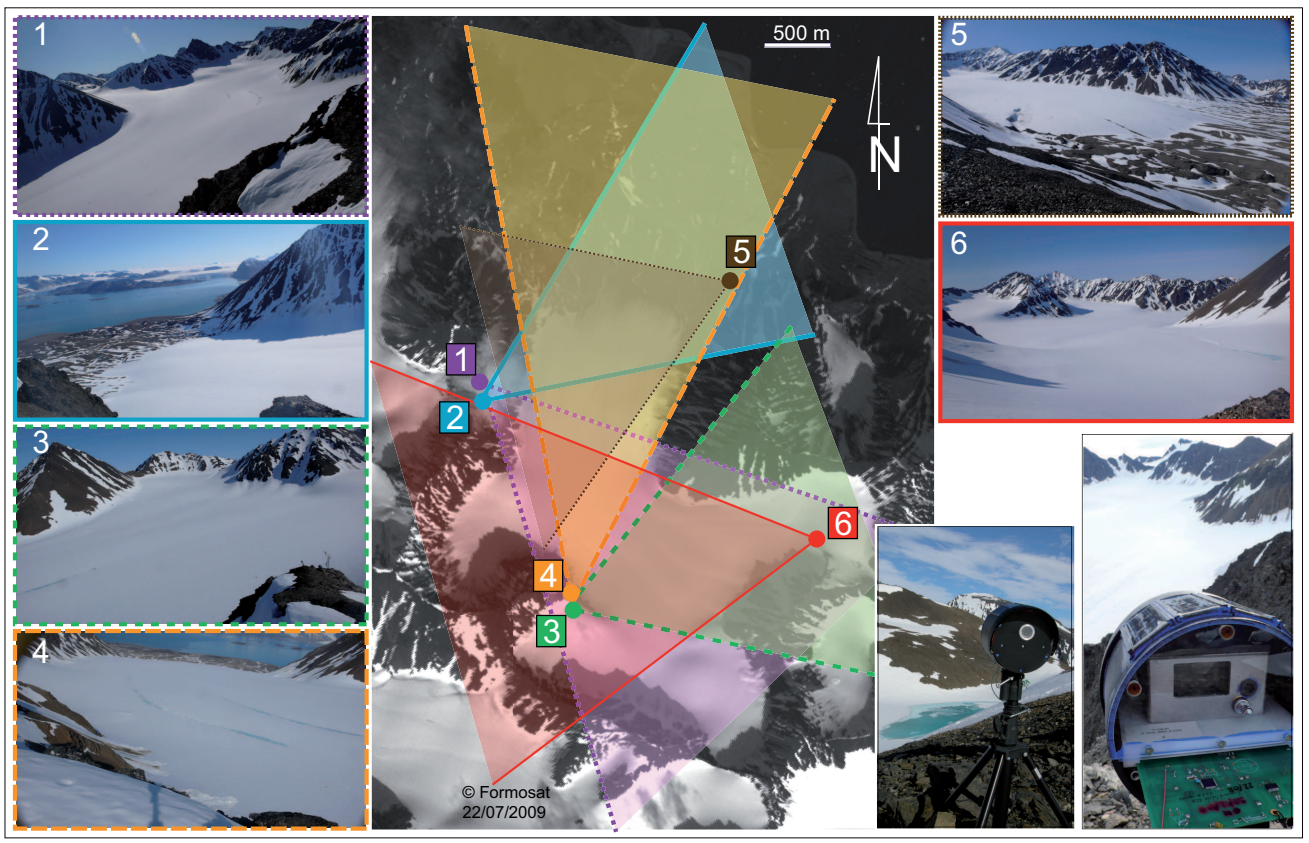

Figure 2: The network of automated digital cameras observing the Austre Lovénbreen glacier basin. Bottomright: a double enclosure keeps the digital camera in a dry atmosphere while a dedicated low-power microcontroller based electronics controls the power to the camera at preset time intervals.

card). The wide angle lens, selected as the default setting at power up, is suitable for imaging the nearby small glacier basin: the furthest topic of interest is located $1,700 \mathrm{~m}$ away, as opposed to other similar references aimed at observing from more than $4 \mathrm{~km}$ away [9]. Arctic weather conditions, with wide temperature variations between shadow and sunlit conditions, or electrostatic buildup during snow storms, appear as significant electronics reliability limiting factors.

With this setup, oblique view pictures are gathered with high time and spatial resolution (the pixel size is at worst $0.46 \mathrm{~m} \times 0.46 \mathrm{~m}$ considering the lens aperture), covering $96 \%$ of the glacier surface. Beyond the appropriate sensor resolution, the camera locations selected with safety and ground stability in mind provide a nearly full coverage of the glacier (Fig. 2). We have selected, as a compromise between limited power consumption and improving the chances of appropriate weather and lighting conditions, the acquisition of 3 images every day at a fixed hour set to $7 \mathrm{~h}, 11 \mathrm{~h}$ and $15 \mathrm{~h}$ Coordinated Universal Time (UTC), corresponding 
to $8 / 12 / 16 \mathrm{~h}$ mean solar time at this longitude). Hence, weather permitting, a daily coverage of the glacier condition is guaranteed by this instrument network, providing a complement to space-borne satellite imagery whose availability is strongly dependent on weather conditions and satellite programming over the region of interest.

After selecting the 6,500 usable pictures for a given year, the resulting images must be converted from oblique view to zenithal projection to comply with the requirements of a quantitative analysis [17].

A detailed analysis of the success rate of this instrument network is provided in Fig. 3: out of an expected 6570 pictures to be gathered during one year (April 1st 2009-March 30th 2010) by the 6 cameras, we have recorded 3921 pictures, or $60 \%$, including the full date and time informations in the EXIF header. When focusing on the hydrological year spanning from April 1st 2009 to September 30th 2009, the success rate increases to 73\%, with 2411 recorded pictures out of an expected 3294: the solar pannels used to power the camera real time clock are only functional when the sun rises over the horizon, hence the poorer rate achieved when including the winter season. The winter season is anyhow characterized with dark pictures hardly usable for snow cover analysis, and is not considered during the image processing step.

A camera is considered successful if a picture has been grabbed during a given date, and if a correct date (embedded real time clock onboard the camera still powered) is associated to the EXIF header of these images. Considering that weather conditions might be the most significant factor affecting the proper working of the embedded electronics, the bottom chart (Fig. 3) displays the variation of the air temperature and precipitation in $\mathrm{Ny}$-Ålesund during the same period: temperatures fluctuating around $0^{\circ} \mathrm{C}$, associated with condensation, appear as a significant factor of erratic behaviour of the electronics (June 2009 and October 2009). One parameter not displayed here is wind velocity: strong winds are associated with electrostatic charge buildup which might yield to microprocessor reset.

Digital image processing is performed in three steps. First, a geometric correction aims at projecting the images to a zenithal view and yield a mosaic of pictures covering the region 


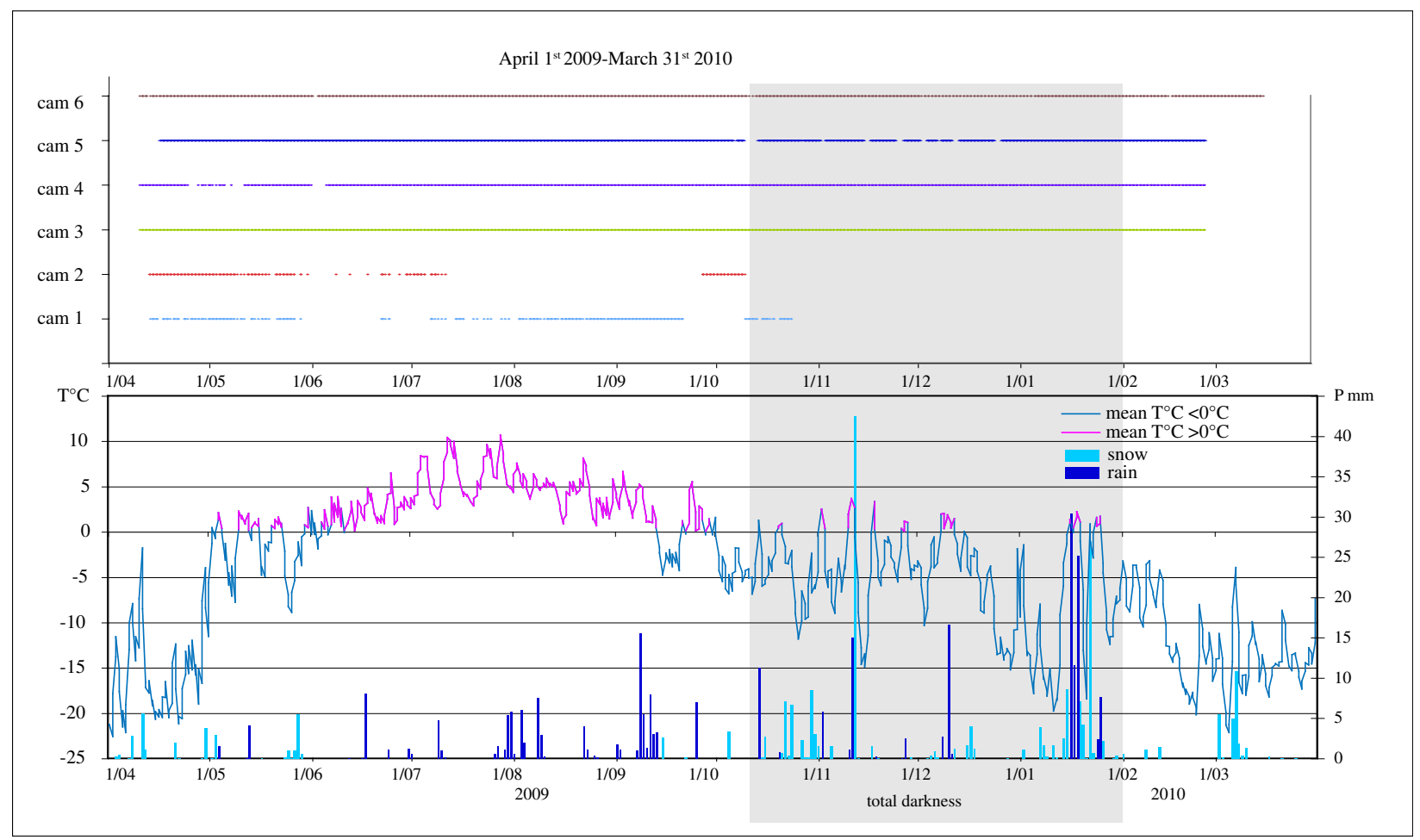

Figure 3: Chart sumarizing the success rate of the cameras located around the Austre Lovénbreen basin during the 2009 hydrological season, and associated weather conditions.

of interest of the glacier. Secondly, with the objective of measuring the snow coverage in mind, specific image sets for which sudden snow cover evolution is observed are selected: these pictures are assembled as mosaics in order to compute the snow covered and iceexposed area fractions. Finally, the snow covered area delimitation on the mosaics with daily resolution over a whole melt-season is performed manually.

\subsection{Geometric correction}

The geometric correction strategy [17] is based on the use of geolocated markers positioned on the glacier surface. The GPS position of a hundred $2 \mathrm{~m} \times 2 \mathrm{~m}$ flags located on the whole glacier surface is measured (Fig. 4 a-c) in order to compensate for the lack of Ground Control Points (GCP), an issue often met when processing images in Arctic areas [16, 1]. The most challenging aspect of these processing steps is the identification of which flags are seen on each picture, requiring manual processing and a good knowledge of the field. 
One reference picture from each oblique-view camera on which all flags are clearly visible is used for identifying the pixel position of each flag (Fig. $4 \mathrm{~d}$ ). In addition, a satellite image including the geographic coordinates of each flag is mapped over the DEM in order to simulate similar viewing conditions under the ArcScene module of ArcGIS (Fig. 4 e). The identification is achieved by comparing the oblique view picture with the 3D simulation. These flags complement identifiable natural features on the slopes used as GCP in order to generate a robust geometric correction model based on Delaunay triangulation (Fig. $4 \mathrm{f}$ ). The resulting geometrically corrected photo is mapped on the satellite image to assess the quality of the processing (Fig. $4 \mathrm{~g}$ ).

\subsection{Snow melt event selection}

Following a classification step aimed at identifying the images with poor visibility (fog, clouds, water condensation on the camera lens, total darkness) in order to select the most interesting pictures, the photo dataset is available as contact prints on which significant snow melt events are readily visually identified. This selection step also allows for the removal of unusable pictures due to poor weather conditions, and identify missing pictures within the dataset due to electronics or battery failures. Nevertheless, unusable pictures in terms of snow cover analysis due to poor visibility provide valuable qualitative informations since they are often indicators of sudden weather events, either strong winds or precipitations.

Each melt event is characterized by a significant retreat of the ice-snow boundary as seen on the oblique view pictures. For a given day, depending on the availability of pictures from the cameras and on the lighting conditions, the best combination of images gathered during a single day, possibly at different times, is manually selected in order to improve the visibility of the phenomena under investigation. While some images include significant informations on the snow melt, quantitative processing is impossible due to water and frost condensation on the outer lens of the camera enclosure. Following this detailed analysis of the contact prints, the relevant dataset is selected for further processing. 


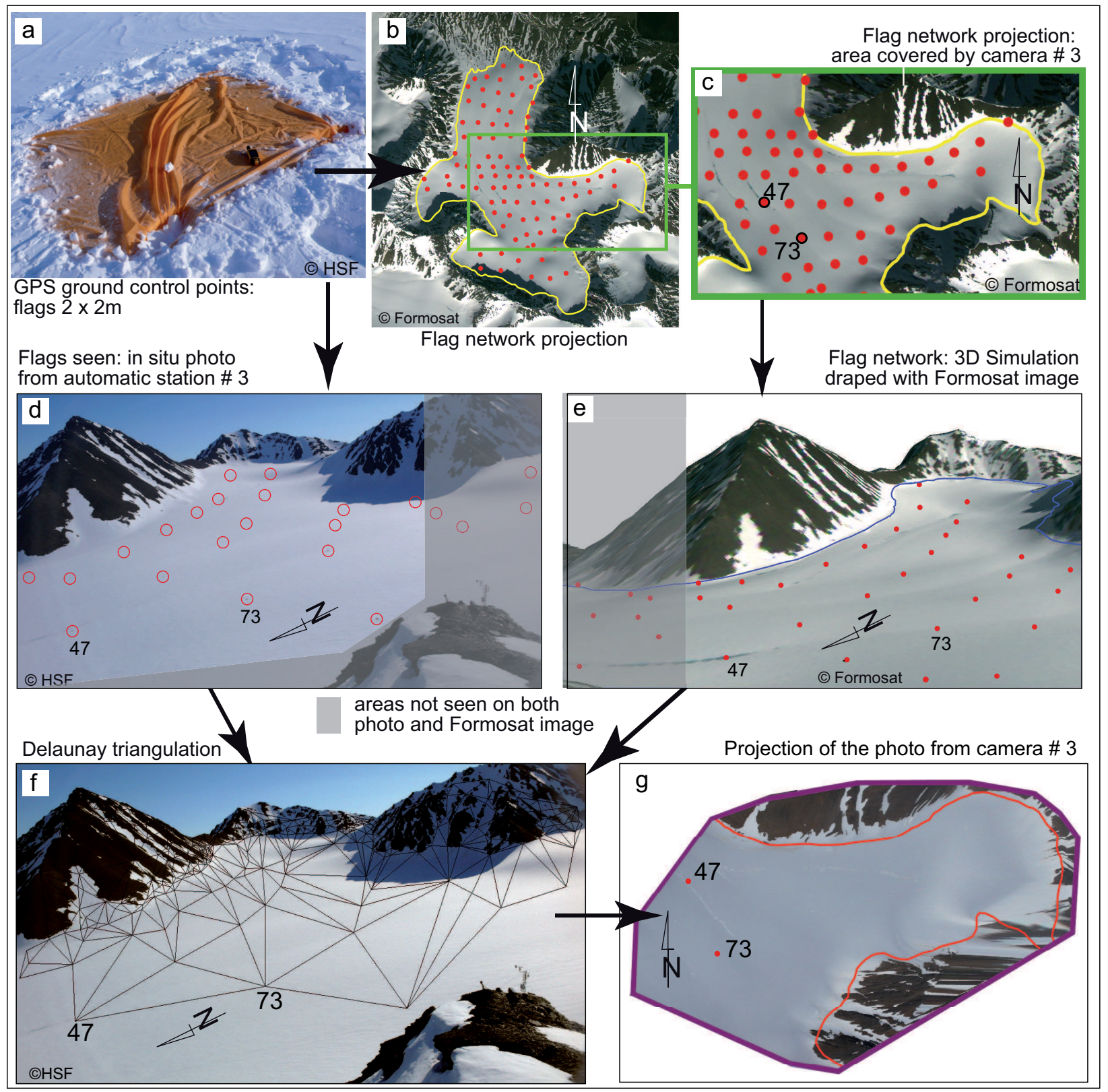

Figure 4: Signal processing steps requiring the preliminary measurement of the position of ground control points over the glacier surface. A significant issue is the interpretation of the pictures in order to locate these features and identify which flag is located at known positions.

\subsection{Picture mosaics}

For a given date selected because it exhibits a significant melt event, we wish to overlap some of the pictures representative of the phenomena under investigation in order to generate 
a zenithal projected mosaic compatible with a quantitative analysis and comparison with satellite images. The selection of the overlap order is performed for best visual results. The mosaic quality is compared to reference satellite orthorectified images for assessing the positioning as well as the glacier boundary: once the mosaic is performed by overlapping the geometrically corrected images, a visual control assesses the result quality in order to avoid any chance of poor interpretation.

We have decided not to automate this mosaic generation step based on the Erdas software: although time consuming, the visual quality assessment is mandatory for the best quantitative exploitation. For instance, when unsuitable deformation is observed on the mosaics with respect to the satellite images, additional GCP can be added to compensate for the divergence of the geometric correction algorithm, as seen for example on bedieres flowing late during the melt season which are not considered as initial GCP. Using one image from each ground-based cameras, mosaics from 5 or 6 overlapping pictures are obtained (Fig. 5)

\section{Results}

In 2009, the melt season under investigation spans from the beginning of July to the end of August, during 43 days. From the first to the last visually identified melt events, one might theoretically look for 43 daily mosaics and 129 mosaics with 4 hour time resolution. Considering the unusable or missing pictures, the available dataset allows for the generation of mosaics of the necessary picture subset to define the ice-snow boundary for 39 days. This dataset allows for the regular monitoring with daily resolution of the snow cover. The quantitative analysis of the picture mosaic is performed by manually defining the snowice boundary, visible as a significant color change in the zenithal view. From the glacier boundary and this snow-ice limit, we compute a snow cover fraction of the glacier (Fig. 6).

Repeating this process for all significant events during the melt season, a snow cover fraction calendar is generated (Fig. 7), which provides the basic data for further snow cover dynamics observation.

A detailed analysis of the melt season shows that the phenomenon is discontinuous, with successive steps. Based on the observations on the raw photos gathered during the 43 days, 


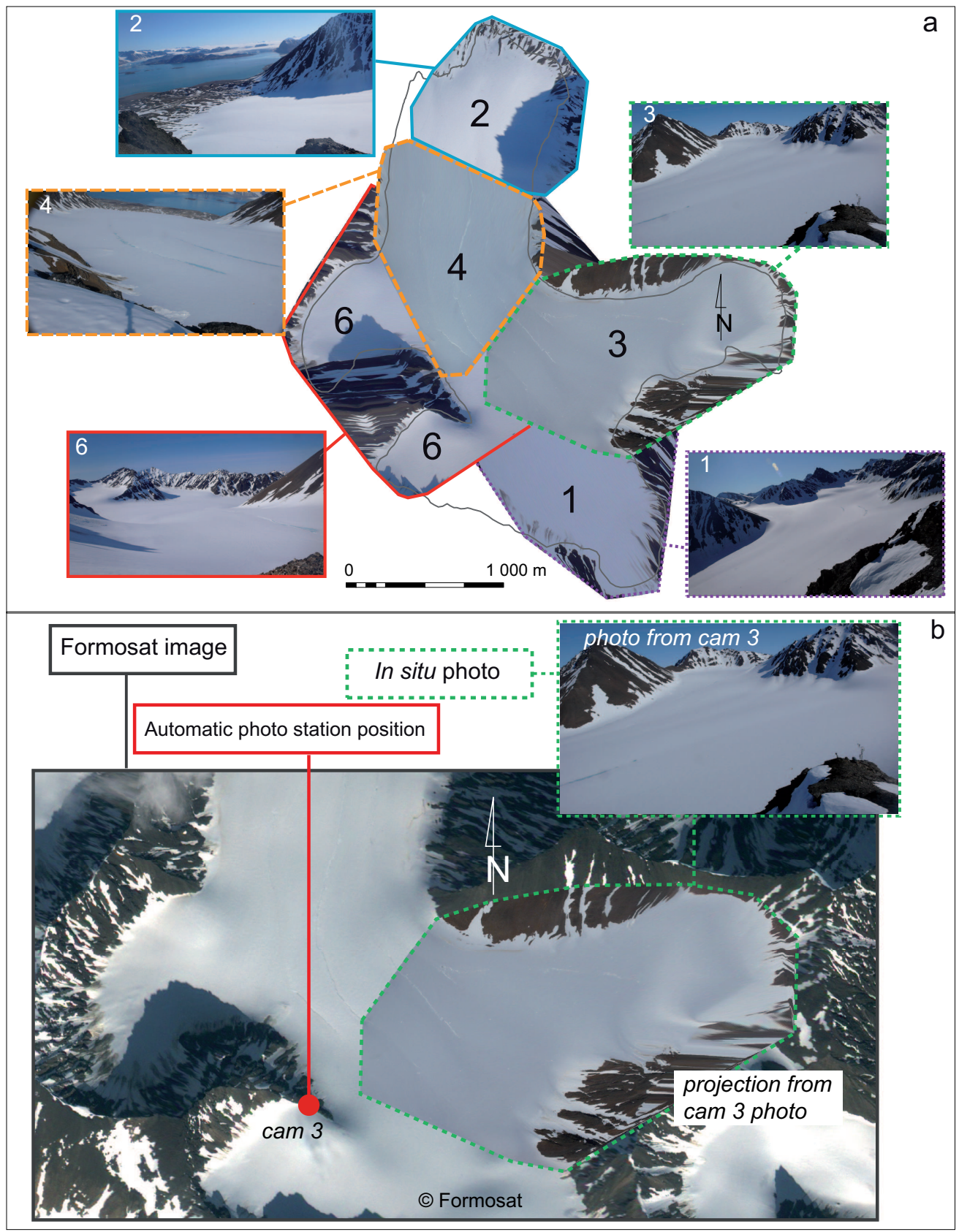

Figure 5: Comparison of the original oblique-view picture, and the same dataset geometrically corrected in order to assemble a mosaic of the zenithal view of the glacier (a). The quality of the geometric correction is assessed by comparing with a reference satellite image acquired the same day (b). Here, photos from 5 cameras have been processed to cover the whole glacier. 


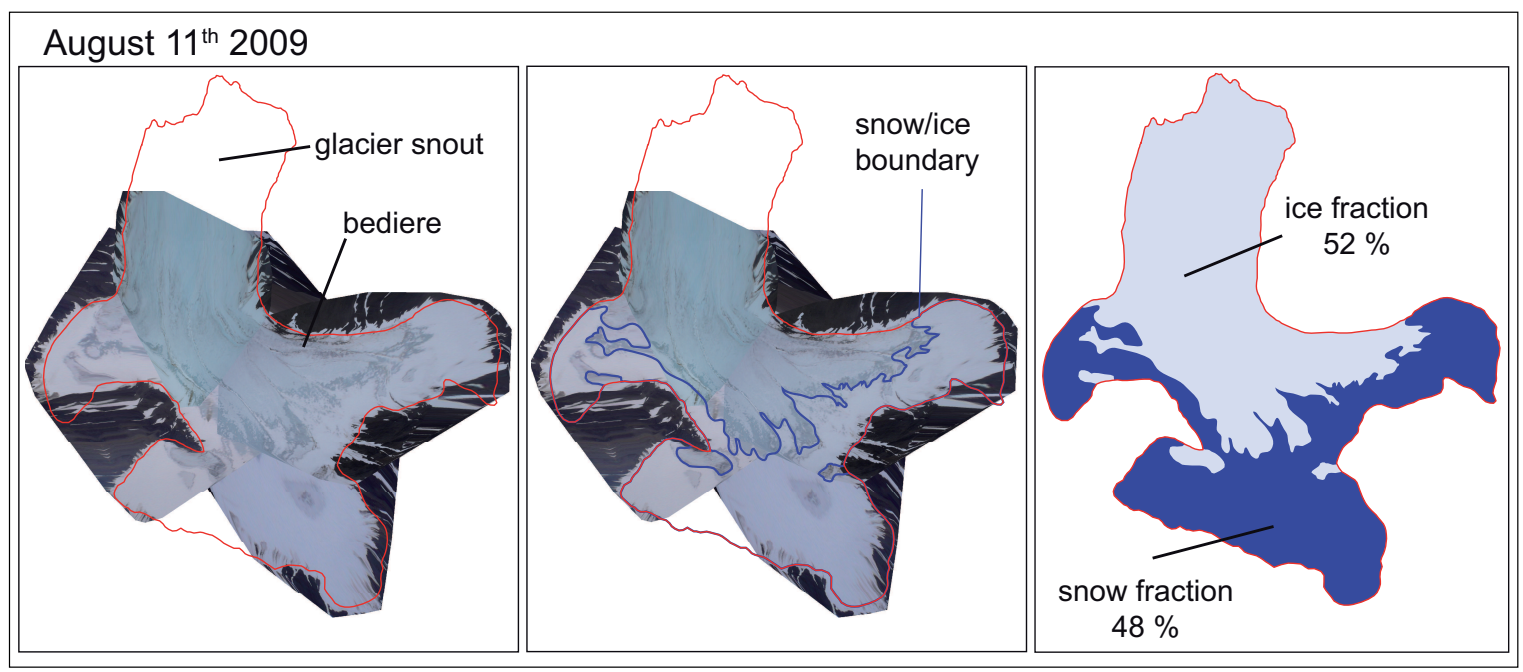

Figure 6: Mosaic of 4 photos acquired August $11^{\text {th }}$ processed to determine the snow-ice boundary.

only 12 events, during which the snow cover significantly varies, are observed (Fig. 7) and deserve the mosaic assembly.

During the 2009 melt season under consideration here, we identify 4 steps during which the glacier variation starts from a $100 \%$ snow cover condition (July $10^{\text {th }}$ ) to reach at the end of the melt season a 37\% snow cover (September $12^{\text {th }}$, Fig. 7). Following this date, the first snow fall again yields a 100\% snow coverage. These steps are correlated with the location at which the process occurs: the first step is concerned with the glacier snout. The second and third phases are located where ice flows from the upstream cirques converge, close to the central area of the glacier: in this flattest region of the glacier, water storage yields slow snow cover variations with multiple small events. The last phase is characterized by a stabilization of the snow cover downstream of the accumulation cirques.

During these sudden melt events, the ice-snow boundary always brutally rises before stabilizing. The snow cover is stable between the melt events. High resolution images allow for the qualitative observation of rare events, such as the snow cover creeping downstream (Fig. 8). This phenomenon, recorded 3 times in 2009, occurs when the capillary cohesion of the snow cover reaches saturation, and is thus mainly associated with water concentration in the snow cover [6]. 


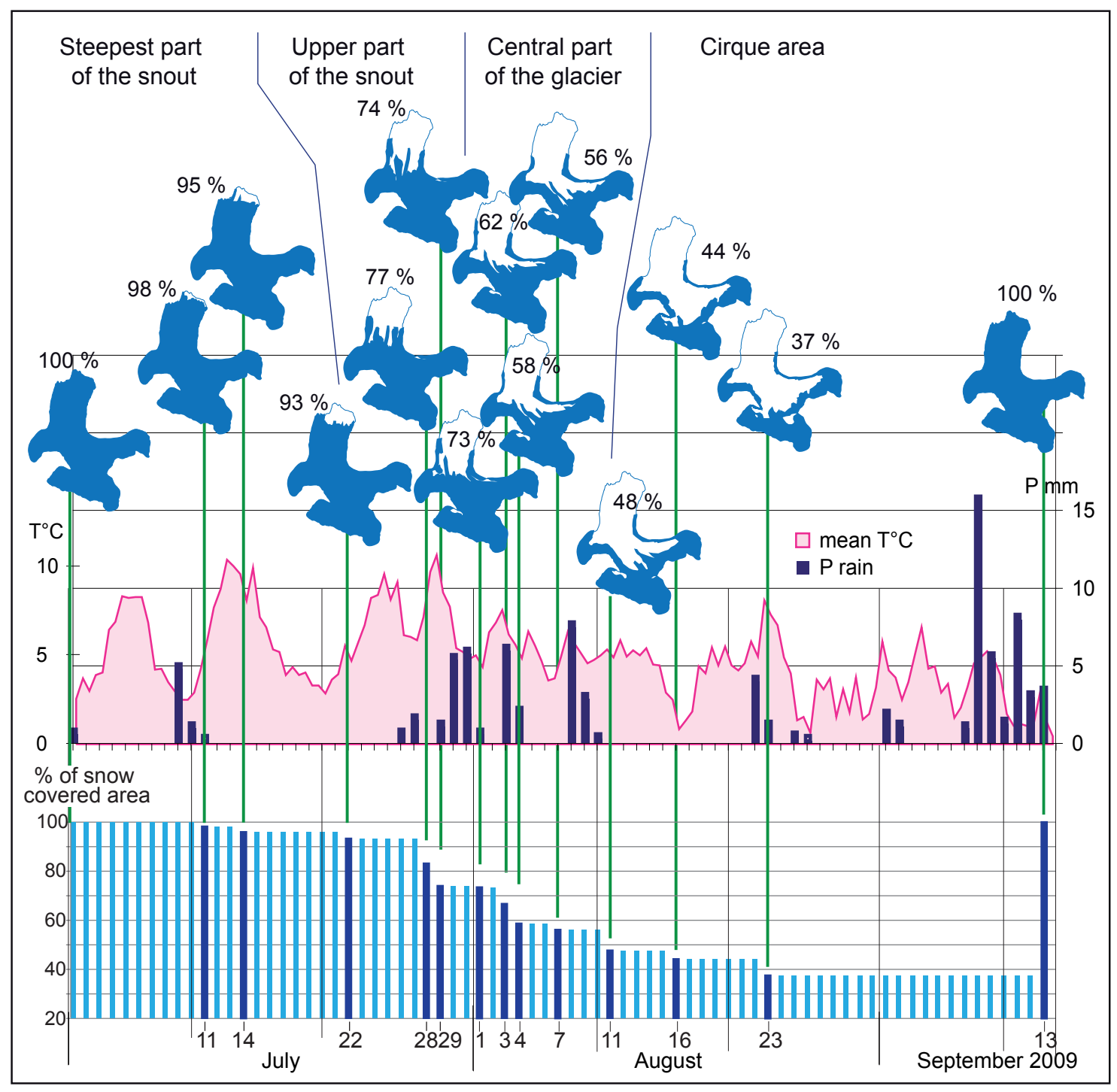

Figure 7: Top: snow melt over one season is separated in four main phases, with a snow cover evolution from $100 \%$ to the final value of $37 \%$ over the glacier area. Bottom: the generation of mosaics allows for a calendar of the melt rate in which the snow cover variation is compared to weather conditions (precipitations and temperatures in Ny-Ålesund, 6 km from the Austre Lovénbreen; data provided by Meteo Norsk).

\section{Discussion}

\subsection{Image processing}

From a technical point of view, we have considered the automated classification and generation of the mosaics as relevant due to the huge number of pictures $[24,23,4]$. The results 


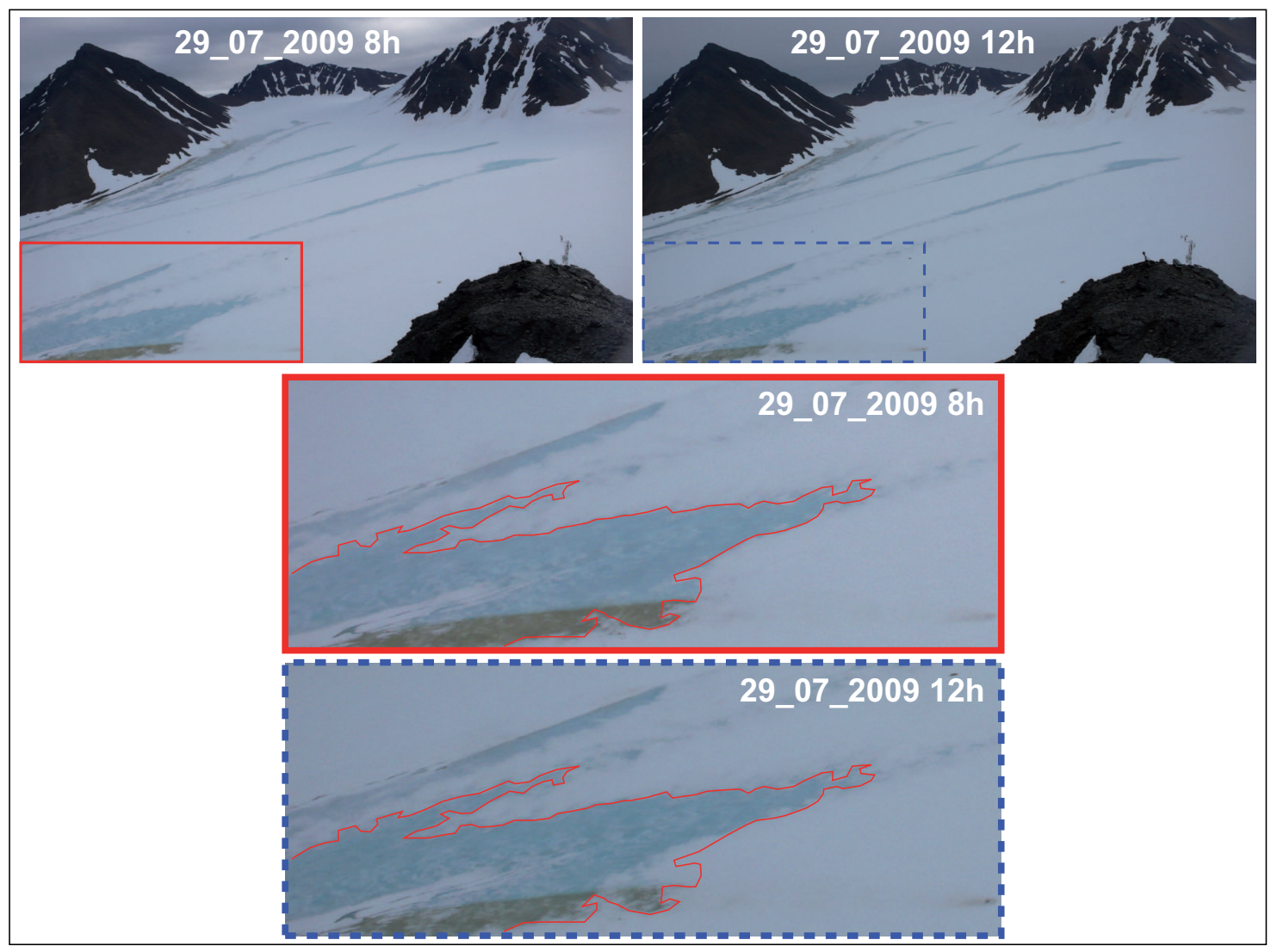

Figure 8: Creeping of the snow cover has been recorded at the snow-ice interface three times in 2009: here a zoom on the set of photos from camera 3 captured July $29^{\text {th }}$.

we obtained were not conclusive when attempting to classify the whole set of images from a given camera due to the large differences in snow coverage and exposed rocks and boulders between images obtained in the beginning and end of the season. Although automating the classification on a subset of images saves time by removing unusable pictures in this context and allowing the user to focus on the significant contact prints, the lengthy manual processing provides the opportunity of visually identifying interesting phenomena. Working on a dedicated region of interest rather than on the whole picture might improve the classification scheme by reducing the influence of weather conditions.

The automation of mosaic generation appears challenging due to the better capability of the human eye to select which picture to put on top of the stack in order to build the mosaic, 
and thus improve the resulting mosaic quality by enhancing the phenomena under investigation. Both shadows in good weather conditions and low cloud cover appear as possible factors for moving a picture towards the bottom of the stack while rising the contribution of the pictures least disturbed.

At the end, the lack of automation was also validated by the few significant events yielding a reasonable number of pictures to be processed: this conclusion would certainly differ if 43 mosaics had to be generated and analyzed.

Considering our initial goal of observing and quantifying the snow cover melt dynamics, we conclude that not all the images are needed at a given date. While obtaining a mosaic including contributions from all 6 cameras provide satisfactory technical and visual results at a given time, the quantitative analysis of ice-snow boundary identification and snow cover ratio over the glacier surface only requires 2 or 3 pictures under most conditions. In this particular example, once the snow cover has completely disappeared from the field of view of the downstream camera (camera \# 2, Fig. 2), processing the images from this instrument is no longer mandatory. Similarly, identifying the ice-snow boundary on the downstream looking cameras means that the images from the upstream looking cameras are no longer needed to compute the snow cover fraction over the glacier surface.

Consistent with field trip observations, only a few melt events are relevant. Indeed, only 12 such events were identified during the 2009 melt season, justifying the removal of some of the melt models. As an example, linear ice-snow boundary motion as used in [19] is inconsistent with the observations.

\subsection{Snow cover}

The melt process starts earlier than the first bare ice surface observation, while the icesnow boundary evolution provides information on the snow cover disappearance dynamics.

Camera photos only provide a binary information of ice or snow presence onto the glacier. Since they do not provide any snow thickness information, the snow cover dynamics cannot be analyzed in terms of melt volume. The motion of the snow-ice boundary deduced from the picture set must be complemented with field measurements (snow thickness and density, 
air temperature) to quantify the melt rate on each point of the glacier. Indeed, these binary ice/snow glacier coverage maps provide the required data to feed a degree-day melting model in complement to the daily evolution of the glacier thermal state $[2,14,25]$. In such a model, the melt coefficient is dependent on the nature of the glacier surface which includes such effects as albedo and heat capacity. Snow cover acts as a protective layer which delays ice melt [8].

Hence, a common melt process is applied to the whole glacier: water generated by the melt of the upper part of the snow cover accumulates in the snow until capillary cohesion ruptures and water flows at the snow-ice interface. Snow cover dynamics is thus interpreted in terms of glacier topography:

- the observation of a fast change of the ice-snow boundary on the snout is not only associated with a thinner snow cover and increased temperature but also a steeper slope inducing faster runoff,

- the central part of the glacier exhibits a similar process, but with a water-filled snow swamp: the six central steps observed in Fig. 7 exhibit a slow snow-ice boundary motion on this central area while we interpret this slow process as a consequence of the lack of slope which prevents the swamp from evacuating.

The stream network on the ice surface only organizes once all the snow has been removed: before this process takes place, water circulation is diffuse at the ice-snow interface and takes the snow away.

The last phase is characterized by a stabilization of the snow-ice boundary below the cirques, associated with a reduction of the water flow and snow melt. Since the snow melt rate is related to the snow stock, the thinner the snow cover, the lower the melt potential. However, water circulation processes throughout the whole snow cover make this simple statement much more complex [6].

Furthermore, we provide a calendar of the snow melt dynamics (Fig. 7) related in this paper to the weather chronicles acquired at the weather station of $\mathrm{Ny}$-Ålesund and exhibiting 
significant melt events: these dates are either associated with unusually high temperatures and/or liquid precipitations.

1. The most intuitive cause of melt is temperature rise: the melt events dated July 14th and 22nd are solely associated with temperature increase while no precipitation occurs at this time,

2. some melt events follow significant rainfall, often associated with temperature increase: the events dated July $11^{\text {th }}$, August $11^{\text {th }}$ and August $23^{\text {rd }}$ follow rain by 1 to 2 days. This delay indicates that melt is not associated with energy brought by the liquid water inducing snow fusion, but rather with capillary diffusion of the liquid water in the snow cover, yielding loss of cohesion.

3. some melt event are immediately associated with rain as well as temperature increase: most significantly, the long rain period from July 28th to August 4th as well as August $7^{\text {th }}$ exhibit multiple snow cover retreat,

4. finally, a single event occurring August $16^{\text {th }}$ remains unexplained since it is neither associated with precipitation nor temperature rise. Mechanical dynamics of the snowcover could explain it by drainage of the top snow swamps and by a break in the water-supersaturated snow.

\section{Conclusion and perspectives}

The novel approach of generating mosaics of geometrically corrected ground-based digital camera pictures provides the means for a precise monitoring of the snow cover dynamics over a small Arctic glacier basin. Its contribution to the hydrological processes is thus assessed.

The processing algorithm follows three main steps:

1. identifying and geolocating on one representative picture from each camera ground control points, followed by geometrical corrections of the image,

2. assembling mosaics of the relevant events during one snow melt season,

3. manually drawing the ice-snow boundary over the glacier surface, and computing the relative area of the snow-covered fraction of the glacier. 
We observe, from the resulting dataset covering one melt season, the discontinuous melt rate of the snow cover. A few significant snow melt events are observed, associated either with temperature increase or liquid water diffusion in the snow. Liquid water, either provided as rain or surface runoff on the glacier, appears as a significant accelerating factor defining melt rate beyond the influence of air temperature.

Further study aim at exploiting these binary ice/snow cover maps in a degree-day melting model, crossing the information of snow-ice presence with daily thermal state of the glacier. From these computations, we will provide the potential daily water volume produced by melt, and compare these with hydrological measurements performed downstream in the moraine. The expected result aims at a better understanding of the hydrological processes in a polar glacier region, and most significantly the snow or ice contribution to the runoff during the melt season.

\section{Acknowledgements}

Funding for this research program was provided by the French National Research Agency (ANR) Hydro- Sensors-FlOWS program, IPY \#16 program, and IPEV.

\section{References}

[1] Berthier, E., Arnaud, Y., Baratoux, D., Vincent, C., Remy, F., 2004. Recent rapid thinning of the "Mer de Glace" glacier derived from satellite optical images. Geophysical Research Letters 31, L17401.

[2] Braithwaite, R., 1984. Calculation of degree-days for glacier-climate research. Z. Gletscherkd. Glazialgeol 20, 1-8.

[3] Buus-Hinkler, J., Hansen, B., Tamstorf, M., Pedersen, S., 2006. Snow-vegetation relations in a High Arctic ecosystem: Inter-annual variability inferred from new monitoring and modeling concepts. Remote Sensing of Environment 105, 237-247. 
[4] Casey, K., Kääb, A., Benn, D. I., 2011. Characterization of glacier debris cover via in situ and optical remote sensing methods: a case study in the Khumbu Himalaya, Nepal. The Cryosphere Discuss. 5, 499-564.

[5] Corripio, J., 2004. Snow surface albedo estimation using terrestrial photography. Int. J. Remote Sensing 25 (24), 5705-5729.

[6] Dewalle, D., Rango, A., 2008. Principles of snow hydrology. Cambridge University Press.

[7] Dowdeswell, J., Hagen, J., Björnsson, H., Glazovsky, A., Harrison, W., Holmlund, P., Jania, J., Koerner, R., Lefauconnier, B., Simon, C., Ommanney, L., Thomas, R., 1997. The mass balance of circum-arctic glaciers and recent climate change. Quaternary research 48 (114), QR971900.

[8] Dumont, M., Sirguey, P., Gardelle, J., Arnaud, Y., Durand, Y., 2010. Retrieving surface glacier albedo using spatial and terrestrial remote sensing data. assimilation of albedo into snow model CROCUS to simulate distributed mass balance on Saint Sorlin glacier (French Alps). In: Cold Regions Hydrology Workshop (ESA).

[9] Farinotti, D., Magnusson, J., Huss, M., Bauder, A., 2010. Snow accumulation distribution inferred from time-lapse photography and simple modelling. Journal of Geophysical Research, F010114.

[10] Hagen, J., Eiken, T., Kohler, J., Melvold, K., 2005. Geometry changes on Svalbard glaciers: mass-balance or dynamic response ? Annals of Glaciology 42, 255-261.

[11] Hinkler, J., Ørbæk, J. B., Hansen, B., 2003. Detection of spatial, temporal, and spectral surface changes in the Ny-Ålesund area $79^{\circ} \mathrm{N}$, Svalbard, using a low cost multispectral camera in combination with spectroradiometer measurements. Physics and Chemistry of the Earth 28, 1229-1239.

[12] Hinkler, J., Pedersen, S., Rasch, M., Hansen, B. U., 2002. Automatic snow cover monitoring at high temporal and spatial resolution, using images taken by a standard digital camera. Int. J. Remote Sensing 23 (21), 46694682. 
[13] Humlum, O., 2004. Mapping snow cover duration, avalanches and other geomorphic processes by automatic digital cameras, Longyeardalen, Svalbard - a project funded by the University Courses on Svalbard (UNIS) 2000-2005. UNIS, Department of Geology, Svalbard.

URL http://www.unis.no/research/geology/Geo_research/Ole/mapping_snow_ cover_duration.htm

[14] Johannesson, T., Sigurdsson, O., Laumann, T., Kennett, M., 1995. Degree-day glacier mass balance modelling with applications to glaciers in iceland, norway and greenland. J. Glaciol 41 (138), 345-358.

[15] Keller, M., Beutel, J., Thiele, L., 2009. Mountainview - precision image sensing on high-alpine locations. In: Proc. 6th European Conference on Wireless Sensor Networks (EWSN 2009).

[16] Korona, J., Berthier, E., Bernard, M., Rémy, F., Thouvenot, E., 2009. SPIRIT. SPOT 5 stereoscopic survey of polar ice: Reference images and topographies during the fourth International Polar Year (2007-2009). ISPRS Journal of Photogrammetry and Remote Sensing 64, 204-212.

[17] Laffly, D., Bernard, E., Friedt, J.-M., Martin, G., Tolle, F., Marlin, C., Griselin, M., 2011. High temporal resolution monitoring of snow cover using oblique view groundbased pictures. Polar Record in press.

[18] Lefauconnier, B., Hagen, J., 1990. Glaciers and climate in svalbard: Statistical analysis and reconstruction of the Brøggerbreen mass balance for the last 77 years. Annals of Glaciology 14.

[19] Li, H.-Y., Wang, J., 2010. Simulation of snow distribution and melt under cloudy conditions in an alpine watershed. Hydrol. Earth Syst. Sci. Discuss. 7, 3189-3211.

[20] Moholdt, G., Nuth, C., Hagen, J., Kohler, J., 2010. Recent elevation changes of svalbard 
glaciers derived from ICESat laser altimetry. Remote Sensing of Environment 114 (15), $2756-2767$.

[21] Newbery, K., Southwell, C., 2009. An automated camera system for remote monitoring in polar environments. Cold Regions Science and Technology 55, 47-51.

[22] Nuth, C., Kohler, J., Aas, H., Brandt, O., Hagen, J., 2007. Glacier geometry and elevation changes on svalbard (1936-90) : a baseline dataset. Annals of Glaciology 46, 106-116.

[23] Racoviteanu, A., Williams, M., Barry, R., 2008. Optical remote sensing of glacier characteristics: A review with focus on the Himalaya. sensors 8, 3355-3383.

[24] Shukla, A., Gupta, R., Arora, M., 2009. Estimation of debris cover and its temporal variation using optical satellite sensor data: a case study in Chenab basin, Himalaya. Journal of Glaciology 55 (191), 444-452.

[25] Zhang, Y., Liu, S., Ding, Y., 2006. Application of a degree-day model for the determination of contributions to glacier meltwater and runoff near keqicar baqi glacier, southwestern tien shan. Ann. Glaciol. 43, 280-284. 